Revista Mídia e Cotidiano

Artigo Seção Livre

Volume 12, Número 1, abril de 2018

Submetido em: 04/03/2018

Aprovado em: 28/04/2018

\title{
SAPIENS E DEMENS: o conhecimento comum na obra de Joseph Mitchell
}

\section{SAPIENS AND DEMENS: common knowledge in Joseph Mitchell's reporting}

\author{
Mateus Yuri PASSOS ${ }^{1}$
}

\section{Resumo:}

Neste trabalho, procuramos identificar os esforços de Joseph Mitchell para apresentar, em seus perfis e reportagens produzidos para a revista The New Yorker, aquilo que Michel Maffesoli denomina "conhecimento comum", aqui colocado em diálogo ao conceito de "ideologia do cotidiano" proposto por Mikhail Bakhtin/Valentin Volóchinov. Desse modo, percebemos uma estratégia de reportagem bastante polifônica em seu conjunto, em contraponto à reprodução de ideologias hegemônicas - particularmente no gesto do repórter de trabalhar com "pequenos temas", com "fatias de vida", em vez de se debruçar sobre os grandes tópicos que estavam na agenda de discussão da sociedade americana no período que compreende as décadas de 1930 até 1960.

Palavras-chave: Jornalismo literário; Fontes de informação; Joseph Mitchell; Conhecimento comum; Ideologia do cotidiano.

\begin{abstract}
:
In this paper we aim to identify reporter Joseph Mitchell's efforts, in his profiles and reportages written for The New Yorker magazine, towards featuring what Michel Maffesoli calls the "common knowledge,"here associated to the notion of "everyday ideology" proposed by Mikhail Bakhtin/Valentin Volóchinov. Thus, we notice a body of reportage strategy which is strongly polyphonic, instead of reproducing hegemonic ideologies - in particular in the reporter's preference for writing about "Small subjects," "slices of life," instead of focusing on the big topics which were in the American society's agenda during the 1930s-1960s period.
\end{abstract}

Keywords: Literary Journalism; Information sources; Joseph Mitchell; Common knowledge; Everyday ideology.

\footnotetext{
${ }^{1}$ Professor do Programa de Pós-Graduação em Comunicação Social da Universidade Metodista de São Paulo. Doutor em Teoria e História Literária pela Unicamp. E-mail: mateus.passos@gmail.com.
} 


\section{FANFARRA AO SABER COMUM}

Em uma cena na metade do caminho de O Segredo de Joe Gould [Joe Gould's Secret], ao retornar para seu escritório na redação da revista The New Yorker, o repórter Joseph Mitchell encontrou a sala vazia - até alguns minutos antes estava ali Joseph Ferdinand Gould, protagonista de um perfil que Mitchell escrevera para a revista sobre seu empreendimento literário-sociológico - uma imensa e complexa História Oral dos Nossos Tempos que, conforme o repórter acabara de descobrir, existia em sua maior parte nas intenções e na mente de Gould (MITCHELL, 2012). Ao refletir sobre a nãoconcretude da História Oral, o texto envereda por uma digressão que remete a um projeto literário que Mitchell concebera em seus primeiros anos em Nova York, uma espécie de versão norte-americana do Ulisses de James Joyce, em que testemunharíamos a iniciação de um jovem repórter interiorano na vida metropolitana - um retrato do próprio Mitchell, sua voz no romance, análogo em função ao Stephen Dedalus joyceano -, uma obra da qual nunca escrevera uma só linha. Nesse momento, o repórter expressa sua empatia e mesmo certa identificação com Gould, chegando inclusive a concluir que deveria ter sido melhor para o mundo literário que nenhuma dessas obras tivessem vindo à luz.

Porém, como se tornou de praxe mencionar na fortuna crítica de sua produção, todo o conjunto da obra de Mitchell pode ser compreendido como análogo aos esforços de Joe Gould (PASSOS, 2014), pois nela o repórter não apenas buscou ouvir com atenção o chamado everyman ["homem comum"], mas tornar suas experiências e pontos de vista o centro da enunciação, o principal definidor do enfoque e do tom de suas narrativas, em vez de se debruçar sobre os grandes tópicos que estavam na agenda de discussão da sociedade americana no período em que produziu ativamente (1929-1964): a quebra na bolsa de Nova York, a Grande Depressão, a Segunda Guerra Mundial, a Guerra da Coréia, a Crise dos Mísseis. Como o gesto artístico de Aaron Copland ao denominar sua fanfarra para abertura de concertos como Fanfare for the Common $\mathrm{Man}^{2}$, Mitchell empreendeu uma comemoração - aqui compreendida em seu sentido mais amplo de celebração e vigília - às pequenas vitórias e derrotas da vida humana.

\footnotetext{
${ }^{2}$ Inspirada por uma declaração do vice-presidente americano Henry A. Wallace, que em 1942 afirmara que o século XX seria o século do "homem comum", do trabalhador.
} 
Ao preferir retratar a vida de boêmios, de proprietários de pequenos estabelecimentos de comércio ou entretenimento, do presidente de uma ONG que trabalhava contra o uso de palavrões, de indígenas trabalhadores da construção civil, de sonhadores e fracassados, a obra de Mitchell constitui uma antologia daquilo a que Michel Maffesoli (1988) denomina conhecimento comum, pensamento de praça pública. Seu esforço de reportagem foi, especialmente em sua segunda e terceira fase de produção, um empreendimento de compreensão do presente popular que Maffesoli valoriza - o conjunto de distintos valores e saberes cultivados em diversos recônditos da sociedade, mas não reproduzidos ou reconhecidos por suas instâncias oficiais, fortemente contrastado pelo autor em relação à retórica do Estado sobre seu povo e sua cultura. É uma dimensão do conhecimento que valoriza a experiência e a verossimilhança em vez de buscar certezas e cuja finalidade última seria a de atribuir sentido à vida, às ligações afetivas, enfrentar as tribulações e a morte.

Esse princípio de Maffesoli encontra um análogo em Mikhail Bakhtin (2012), que, ao discutir criticamente a popularização da psicanálise freudiana, acaba propondo a noção de ideologia oficial - nutrida e propagada a partir de instituições sociais como Estado e academia -, e em contraponto a ela a ideologia não-oficial, ou ideologia do cotidiano, que em essência pode ser considerada semelhante ao saber comum, ou conhecimento cotidiano - com a distinção de que Maffesoli trata de formas de conhecimento, de dar sentido ao mundo, enquanto Bakhtin/Volóchinov ${ }^{3}$ foca no aspecto político e ideológico dessa contraposição: ambos os aspectos interessam à discussão apresentada aqui.

Essa relevância que Mitchell - e, de forma mais abrangente, os autores que trabalham gêneros de jornalismo literário - reconhece no conhecimento comum está bem afim aos princípios de uma epistemologia compreensiva conforme definida por Künsch, Menezes e Passos (2017): a reunião de diversas formas de saber, não necessariamente

\footnotetext{
${ }^{3} \mathrm{O}$ ensaio referido, O Freudismo, tem autoria disputada, pois inicialmente foi publicado com assinatura de Valentin Volóchinov, membro do círculo de pensadores de Bakhtin, que décadas após a morte de Volóchinov afirmou ser o verdadeiro autor da obra. Como algumas das obras de que Bakhtin assumiu a autoria foram, após investigações recentes, reatribuídas aos autores do Círculo de Bakhtin que as assinaram originalmente - um nova tradução de Marxismo e Filosofia da Linguagem recém-lançada pela Editora 34 traz, pela primeira vez no Brasil, o nome de Volóchinov como autor -, é mais crível que os conceitos trabalhados em O Freudismo, dentre eles os de ideologia oficial e ideologia do cotidiano, sejam considerados volochinovianos, em vez de bakhtinianos (embora sua concepção e articulação se mantenha diretamente em diálogo com a Bakhtin e seu pensamento). Mantemos aqui o crédito de autoria como Bakhtin/Volóchinov unicamente porque a edição brasileira ainda atribui o nome de Bakhtin como autor, porém isso já foi corrigido em edições da obra em diversos países e idiomas.
} 


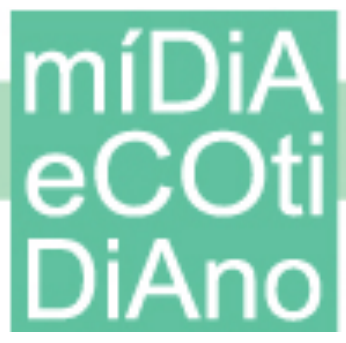

científicos, e o estímulo ao debate igualitário, despido de preconceitos entre eles. $\mathrm{O}$ ambiente compreensivo cultiva, desse modo, a alteridade entre diferentes formas de conhecimento - ou linhas distintas de pensamento dentro de um mesmo segmento, como o acadêmico - e também aquilo a que Mikhail Bakhtin (2010) denomina polifonia - a presença de uma miríade de vozes discursivas distintas, sem a realização de um direcionamento a um fechamento conclusivo, em vez disso fornecendo mais instrumentos para uma abertura interpretativa.

Desse modo, neste trabalho nos norteamos a partir de dois problemas de pesquisa. O primeiro são as maneiras distintas como esse conhecimento comum é articulado na obra de Mitchell; o segundo, os impactos que isso traz em termos de informação jornalística. Trabalharemos com quatro textos oriundos das diferentes fases da produção do repórter (PERRIN, 1983; PASSOS, 2017), selecionados de forma a representar a estratégia de reportagem de Mitchell em cada uma das quatro fases. O primeiro deles é a reportagem "Voodoo in New York, N.Y.", cuja data e veículo originais não foi possível recuperar - o texto integra a coletânea My Ears are Bent, que reúne textos de Mitchell publicados entre 1930 e 1937 nos jornais novaiorquinos The Herald Tribune e The WorldTelegram, onde começou sua carreira, e pertence a um momento em que o repórter dava seus primeiros passos como autor de narrativas.

A seguir, temos o perfil "Lady Olga", publicado originalmente em 3 de agosto de 1940 na New Yorker, integrante da segunda fase da produção de Mitchell, na qual já havia consolidado um estilo e estratégia de escrita próprios, dedicando cada vez mais tempo para conhecer seus personagens e exercitando um diálogo empático que desembocaria numa fase elegíaca - da qual discutiremos o perfil "Mr. Hunter's Grave", publicado originalmente em 22 de setembro de 1956 na New Yorker.

Por fim, será discutido "O Segredo de Joe Gould", publicado originalmente em duas partes nas edições de 19 e 26 de setembro de 1964 - uma das poucas obras de Mitchell publicadas no Brasil, integrante da fase final da produção do autor, em que a narrativa passa da apuração de fatos ao plano da memória, com o cultivo de ensaiosmemoriais baseados em experiências de reportagem e da vida pessoal.

A respeito de cada uma dessas obras serão discutidos os personagens e situações centrais e o tipo de conhecimento comum a que referem, e também o modo como Mitchell 
articula - ou não - suas falas e ideias às de outras fontes. Numa seção posterior do artigo, abrirei o escopo da discussão para fazer uma caracterização do tratamento das fontes no jornalismo literário.

\section{O CONHECIMENTO COMUM COMO FONTE DE INFORMAÇÃO}

Enquanto representação do real, o jornalismo literário pode ser melhor compreendido como um modelo sistêmico jornalístico distinto, ao invés de um gênero ou modalidade agrupada junto às categorias de jornalismo informativo, opinativo, interpretativo etc. (PASSOS; ORLANDINI, 2008). Portanto, ele se contraporia, como modelo, ao jornalismo de pirâmide (PASSOS, 2010), assim denominado por ter como seu produto principal e mais nobre as notícias e reportagens estruturadas na forma da pirâmide invertida encabeçada pelo lead, o qual concentraria em si a unidade informativa essencial de um acontecimento (GENRO FILHO, 2012) - porém, enquanto sistema, o jornalismo de pirâmide, marcado pela separação histórica entre notícia e opinião, abarcaria também os diversos gêneros opinativos e interpretativos associados a essa dicotomia.

O uso de personagens como definidores do real em obras de jornalismo literário é um dos elementos que melhor proporciona a circulação e a condição protagonista do conhecimento comum. No jornalismo de pirâmide o papel de fontes de informação, de acordo com Aldo Schmitz (2011), se configura tanto no auxílio à apuração das notícias, enquanto entrevistados, como no oferecimento de conteúdo próprio para deliberadamente fornecer informações que possam dar origem a pautas de notícias e reportagens podendo, nesse caso, ser consideradas como "um poder que mede forças com o 'poder da imprensa'" (SCHMITZ, 2011, p. 10). Schmitz distingue as fontes entre primárias diretamente envolvidas com fatos - e secundárias - cujo papel é o de analisar e interpretar informações obtidas a partir das fontes primárias, podendo ser ainda classificadas, de acordo com seu status social, como fontes oficiais, empresariais, institucionais, populares, notáveis, testemunhais, especializadas ou referenciais. Stuart Hall et al (2016) defendem ainda que um conjunto específico de indivíduos ocupa um patamar privilegiado enquanto fonte - seja pelo envolvimento direto com eventos em questão ou pelo oferecimento de análises -, a ponto de suas enunciações serem utilizadas para definir o enfoque, o fio condutor da narrativa noticiosa; ou seja, para definir um determinado recorte e uma 
determinada leitura de realidade que serão seguidos numa determinada peça jornalística. Essas fontes, que compreendem as oficiais, empresariais, institucionais e especializadas, são denominadas por Hall e seus colaboradores como "definidores primários", justamente por conta desse papel crucial na condução da produção jornalística.

Em busca de objetividade, o jornalismo de pirâmide confia aos definidores primários o papel de intérpretes da realidade, delegando ao repórter a função de mediador e de "garimpador" de declarações dessas fontes (PASSOS, 2010). Desse modo, podemos afirmar que o jornalismo de pirâmide se fia não em indivíduos para a representação e análise de fatos, mas em instituições - governos, órgãos de polícia e defesa, empresas e, principalmente, os diversos ramos da ciência; e seria justamente o poder institucional dessas organizações, seu prestígio e reconhecimento social, o que conferiria credibilidade tanto a às fontes que as representam quanto ao material noticioso que faz uso delas para tratar de determinado acontecimento.

Esses procedimentos, porém, têm como consequência a reprodução do pensamento hegemônico da ideologia oficial, desenvolvida e reforçada justamente pelo conjunto de instituições que respaldam os definidores primários, e que Bakhtin (2012) contrapõe à já mencionada ideologia do cotidiano, formada pela experiência imediata de indivíduos ligados ou não a essas instituições - e nesse caso parece adequado reforçar a acepção dessa experiência como algo não-mediado, ou seja, anterior à construção da realidade nos meios de comunicação de massa.

A definição da leitura do real por essas fontes, assim como a circulação majoritária de suas declarações, que as hierarquiza num estrato superior de qualidade e credibilidade em relação a outros tipos de fonte, acaba por reforçar o suporte à ideologia oficial e por silenciar e marginalizar outras vozes e possibilidades interpretativas, fenômeno a que Elisabeth Noelle-Neumann (1993) denomina espiral do silêncio.

Por outro lado, enquanto o jornalismo de pirâmide utiliza entrevistados como fontes de informação amparadas e validadas a partir das instituições de poder que representam, no jornalismo literário esses indivíduos se transformam em que, retratados em seu sentir e agir no mundo, têm o reconhecimento de sua fala articulada a partir de suas vivências, que lhes conferiria credibilidade de modo independente de um amparo institucional - o que inclui uma recusa ao expediente de se buscar expertises acadêmico- 


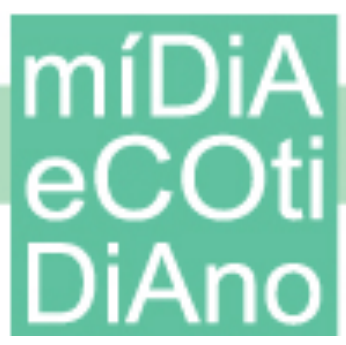

científicas para interpretar ou validar seus enunciados. Podemos atribuir esse comportamento discursivo à postura contra-hegemônica que pautava o Novo Jornalismo norte-americano (PAULY, 1990), que pode ser estendida à tradição do jornalismo literário anglófono como um todo, e possivelmente boa parte dos gêneros de jornalismo literário ao redor do mundo.

$\mathrm{O}$ arranjo discursivo do jornalismo literário, ao privilegiar a experiência e organizar as fontes/personagens de forma mais horizontalizada, se comporta de forma bastante similar à comunidade estendida de pares proposta por Funtowicz e Ravetz (1993), na qual as expertises de determinada área dialogariam em igualdade com nãoespecialistas diretamente interessados ou envolvidos em algum tópico para que se pudesse realizar tomadas de decisão baseadas num diálogo mais plural - verdadeiramente polifônico, nos termos de Bakhtin (2010), uma vez que vozes com discursos efetivamente distintos teriam oportunidade de ser ouvidas sem que algum poder mediador conferisse maior ou menor autoridade a uma parte delas.

Há ainda outro aspecto desse tratamento diferenciado das fontes nos dois modelos jornalísticos que pode ser identificado dentre os pilares da compreensão künschiana (KÜNSCH; MENEZES; PASSOS, 2017): o binômio da compreensão oposta à explicação. De um modo geral, o jornalismo de pirâmide se sente mais à vontade com a resolução de dúvidas, com o didatismo, com a explicação dos fenômenos que acompanha e reforça sua tendência universalizante, enquanto o jornalismo literário adere, de maneiras distintas, ao gesto da compreensão ao deixar que a experiência fale por si, sem sujeitá-la a um afunilamento de seus significados a partir das interpretações de definidores primários.

\section{POSTURAS DE REPORTAGEM}

A trajetória de reportagem de Mitchell cobre pontos distintos, com um tratamento notavelmente bastante diferenciado dos entrevistados ao longo das três décadas em que esteve mais ativo. No volume que reúne seus primeiros anos de reportagem, My Ears are Bent, a gama de personagens de Mitchell abrange desde Mazie P. Gordon, proprietária de um pequeno cinema que passava as madrugadas dando comida ou dinheiro a mendigos revisitada por Mitchell em outro perfil, publicado anos depois na New Yorker - até o 
teatrólogo britânico George Bernard Shaw, um tipo de celebridade que desaparece posteriormente da produção de Mitchell após seu ingresso no semanário, um dos mais prestigiados da imprensa norte-americana.

"Voodoo in New York, N.Y.", uma reportagem sobre o vodu na cidade - palavra oriunda da matriz religiosa vodun do antigo reino africano de Dahomey e que, no uso novaioarquino dos anos 1930, funcionava como um termo abrangente para uma série de práticas de ocultismo - especialmente lojas em que ervas, raízes e incensos originários do vodu religioso são apropriados por homens brancos e comercializados ao lado de bolas de cristal e caixas de ectoplasma. Este texto é um ponto de partida interessante, uma vez que não apenas não contempla com respeito e igualdade esse setor da prática do cotidiano, mas o desqualifica como "primitivo" e "desumano" - em referência ao sacrifício de animais -, imputando um juízo a partir de seu próprio sistema de valores, externo ao das pessoas sobre quem fala - procedimento que desaparece na produção posterior de Mitchell. A reportagem está repleta de trechos como o que se segue:

There is a voodoo doctor in Harlem who uses a Hindu name, anoints his head with oils purchased from a store which also sells incense and candles to catholic churches, "consecrates" the stick he uses in incantations with a prayer written by a minister of the Spiritual Psychic Science Church, and then goes into a mumble-jumble which ends with the sacrifice of a snake he bought in a pet store.

An anthropologist would scream if such a melange were called voodoo, but what else could you call it, except high-and-mighty nonsense? (MITCHELL, 2001, p. 142)

Desenvolvida a partir de observação participante do repórter pelas ruas do Harlem, a reportagem apresenta muitos indivíduos que não nomeia - embora as descrições permitissem sua identificação a quem vivia ali naquela mesma época e lugar; essas pessoas - comerciantes, conjuradores, doutores - não apenas não têm nome, mas raramente têm a oportunidade de falar por si próprias, com algumas exceções. Uma das pessoas que têm a chance de falar é o proprietário de uma loja que fornece material para esses profissionais - que, neste caso, exigiu não ser identificado. Seu papel na reportagem é não apenas relatar o tipo de material comercializado, mas também o de desmistificar o ocultismo como indústria - mencionando as estratégias redacionais de fabricantes para não serem processadas caso seus produtos não apresentem o efeito prometido, e os casos de donas de velhas pensões que comprariam poções para afastar os maus espíritos que as 


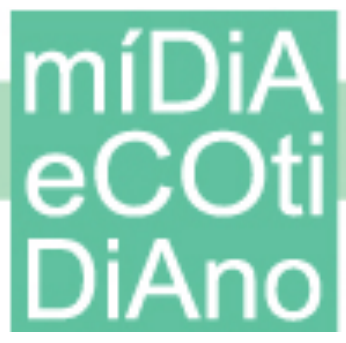

impediriam de receber novos inquilinos, que na verdade seriam poderosos produtos de limpeza que melhorariam o odor desses imóveis. Outros dois personagens são uma policial, não identificada, e a conjuradora Marie Bernard, que a teria enganado - os eventos são contados apenas do ponto de vista da policial. A polícia e o proprietário da loja cumprem o papel de definidores primários da narrativa ao apresentar pontos de entrada e chaves de leitura para observar a temática da reportagem: a da prática fraude grave, com consequências penais, e a inofensiva, que se traveste para auxiliar pessoas ingênuas - ao mesmo tempo, são instâncias de ideologia oficial que buscam "racionalizar" comportamentos tidos como desviantes. De todo modo, o saber comum representado pelo "vodu" passa por um processo de descrédito e desmistificação, subjugado à lógica e aos valores da ideologia oficial.

"Lady Olga", por sua vez, mostra o quanto o amadurecimento profissional, favorecido pelas condições de trabalho excepcionais da New Yorker - para a qual colaborava desde 1933, antes de ser contratado em definitivo em 1938 - contribuiu para aprimorar a empatia com o conhecimento comum nas produções de Mitchell. Embora o título do perfil ostente seu nome profissional, a protagonista é sempre tratada pelo nome de batismo, que usa na vida privada - Jane Barnell, que trabalha como mulher barbada em sideshows em Nova York. A personagem é relembrada em "A Place of Pasts" (MITCHELL, 2015), um dos poucos fragmentos de um livro de memórias que Mitchell jamais concluiu, como um dos três perfilados memoráveis com quem o repórter dialogou; lhe encantava especialmente a saudade que Barnell sentia pela fazenda onde crescera na Carolina do Norte, não muito distante de Fairmont, onde o próprio Mitchell passou sua infância e adolescência.

No perfil de 1940, a caracterização de Barnell e seu ofício, de sua vida, parte não apenas das observações de Mitchell, mas das declarações da própria perfilada - da forma como se via, de como valorava sua vida e o mundo a seu redor: sua adesão fervorosa ao Partido Republicano - embora nunca votasse - e confiança plena nos jornais sensacionalistas de William Hearst; sua decisão de parar de trabalhar em circos porque acreditava que seria logo forçada a aderir a um sindicato, pelos quais tinha aversão; sua antipatia também pelos médicos, que queriam examiná-la, normalizá-la; sua vida com o quarto marido, o ex-palhaço Thomas O’Boyle, e o gato Edelweiss - que sempre que 


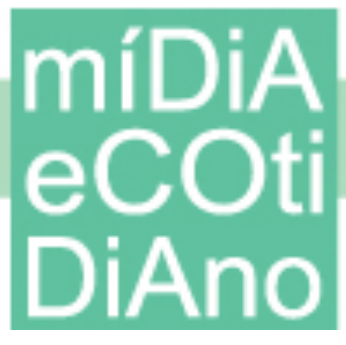

permitido preferia levar para o trabalho, pois sentia pena em deixá-lo sozinho no apartamento da família.

A única outra fonte que aparece com falas no texto é Fred Smythe, empresário de circo que lamenta a recusa de Barnell em aceitar novos contratos de trabalho, enquanto reconhece seu valor como profissional no ramo - a única autêntica no país - e o papel tradicional de mulheres barbadas para o circo na época; de acordo com ele, um circo sem elas seria como um circo sem palhaços. É na caracterização de Barnell como profissional, a partir de observações e dos diálogos com a perfilada, que Mitchell se mostra bastante distante do jovem autor de "Voodoo in New York, N.Y.", tratando com respeito o mundo da entrevistada: o cuidado que tinha com sua barba quando jovem, a cada ano a aparando de acordo com um estilo que estivesse na moda; seu cuidado em escolher o vestuário e seu jeito taciturno no palco, oposto a seu ar alegre na vida privada; seu respeito inclusive por homens que se passam por mulheres barbadas; seu interesse em ver seu velho amigo, Professor LeRoy Heckler, alimentar suas pulgas treinadas. Desta vez, é o ponto de vista de Barnell que dá o tom e as chaves de leitura da narrativa: Mitchell naturalmente apresenta a personagem a partir de sua percepção e de uma série de recortes de caracterização, mas suas idiossincrasias, contradições e valores não são em momento algum subjugados, explicados, por instâncias outras, por exeprtises dos saberes oficiais.

O perfil pertence à mesma fase de "Old Mr. Flood", originalmente publicado na New Yorker com o título "Coffins! Undertakers! Hearses! Funeral Parlors!” em 25 de novembro de 1944, em que uma estratégia de caracterização semelhante é empregada para retratar o modo de vida, valores e angústias de um perfilado. Este, no entanto, é hoje considerado um texto ficcional por ter como protagonista um personagem composto (MARTINEZ; CORREIA; PASSOS, 2015) - Hugh Griffin Flood, funcionário aposentado do setor de demolições -, construído a partir de entrevistas com diversos moradores da região do Fulton Fish Market que, embora concordassem em conversar com Mitchell, não permitiam a ele escrever um perfil sobre qualquer um deles; para que seus esforços não fossem desperdiçados, o editor Harold Ross sugeriu a Mitchell o caminho da ficção para aproveitar o material apurado ao longo de meses (RUNDUS, 2015). Em “Old Mr. Flood”, Mitchell explora seu personagem como um exemplar dos idosos que moravam na região, com foco especial por uma rejeição à engenharia de 
alimentos que constituiria uma parte importante do pensamento e do modo de vida dessas pessoas - o homem se alimentava exclusivamente de peixes e frutos do mar por acreditar que, por serem pescados em ambiente selvagem, seriam o único tipo de alimento ainda não alterado por mãos humanas, e portanto mais saudáveis; alimentava, assim, a expectativa de viver até os 115 anos de idade.

O retrato de outro homem idoso constituiria o centro da narrativa de um dos textos da terceira fase da escrita de Mitchell - “Mr. Hunter's Grave”. George Hunter, o perfilado, vivia em Sandy Ground, uma pequena comunidade de ex-escravos negros no distrito de Staten Island - formada por uma igreja metodista e algo entre quarenta e cinquenta casas; um remanescente de um grupo de criadores de ostras que havia perdido seu ofício devido à poluição, que aguarda a morte e relata a história de como havia planejado um modo de ser enterrado no mesmo jazigo da segunda esposa, Edith - algo impossibilitado porque o coveiro encarregado de enterrá-la deveria ter cavado uma cova dois pés abaixo do que costumava fazer, mas foi incapaz de mudar seus hábitos. Como aponta Martinez (2016), parte da força da narrativa está em Mitchell registrar longas falas permitindo assim que o leitor veja o mundo a partir dos olhos do protagonista - é uma nova estratégia de escrita do repórter, que aqui apresenta a narrativa na forma do conto de uma visita sua à comunidade, desembocando em uma longa conversa com Hunter.

Essa fase da produção de Mitchell, correspondente a quatro perfis e reportagens publicados entre 1950 e 1960 - os demais são "Up in the Old Hotel”, "The Bottom of the Harbor" e "The Rivermen" - foi caracterizada por Noel Perrin como elegíaca por se focar em "sobreviventes" de segmentos sociais de uma Nova York em acelerado processo de desaparecimento, e expressar a nostalgia por um passado irrecuperável senão por seu registro em narrativa - o que se pode notar pela forma como Mitchell articula a narrativa.

A única outra fonte que aparece nominalmente no texto é Raymond E. Brock, pároco da igreja de St. Luke, que apresenta Mitchell à comunidade, qualifica Sandy Ground como relíquia, pouco a pouco sendo abandonada - o cemitério local, inclusive, careceria de cuidados havia anos, com as lápides sendo encobertas por musgo. Como membro do conselho da igreja encarregado do cemitério, o próprio Hunter é tratado no texto como relíquia, como ruína: alguém que ainda lia a Bíblia de cabo a rabo, que havia trabalhado na criação de ostras e testemunhado a ascensão e queda do negócio, que 


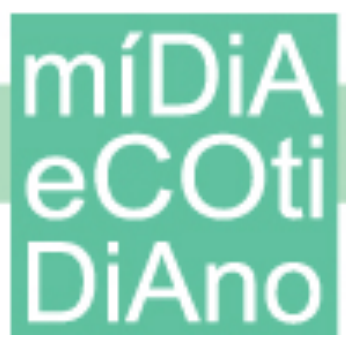

conhecia todas as pessoas enterradas no cemitério - como haviam vivido, como haviam morrido -, uma espécie de encarnação da memória coletiva da comunidade, embora conserve sua individualidade, sua memória e desejos próprios, seus maneirismos.

Do mesmo modo que "Lady Olga", "Old Mr. Flood" e "Mr. Hunter's Grave" apresentam saberes do cotidiano que por vezes discordam e desafiam das instâncias de ideologia oficial - em especial a postura desconfiada do personagem composto Hugh Griffin Flood em relação ao melhoramento artificial de alimentos, à perturbação de uma natureza "imaculada" pela ciência. Novamente, esses discursos e saberes não são relativizados ou explicados - nem pelo filtro do repórter, nem por meio de fontes acreditadas por sua formação ou vinculação a instâncias de poder.

O retrato de personagens por Mitchell chega a um novo patamar em "O Segredo de Joe Gould" - o qual inaugura uma nova fase na produção do autor que não chegou a ser plenamente desenvolvida (PASSOS, 2014; 2017), uma vez que logo após a publicação da obra Mitchell passou a sofrer de um bloqueio de escrita que o impediria de publicar, ou mesmo concluir qualquer outro texto desde 1964 até sua morte, em 1996. Nessa derradeira fase de sua escrita, na qual começou a ser preparado um livro de memórias do qual só pôde produzir três fragmentos - "Street Life", "Days in the Branch" e o já mencionado "A Place of Pasts", publicados na New Yorker entre 2013 e 2015 -, Mitchell já não trabalharia mais com reportagens ou perfis, passando a articular um gênero híbrido que pode ser categorizado como ensaio-memorial; nele, Mitchell não faria mais apurações ou entrevistas para descrever sujeitos e objetos do mundo presente - ainda que se tratassem cada vez mais de remanescentes do passado em vias de desaparecer -, mas trabalharia, a partir da memória de sua experiência e de seu mundo interior as cenas e as reflexões sobre aspectos de Nova York, do condado de Robeson, na Carolina do Norte, onde crescera, e principalmente a respeito de si próprio, de sua relação com esses lugares e seus personagens.

É em torno desses elementos que se dá a toada de "O Segredo de Joe Gould": o foco são as memórias sobre a relação de Mitchell com o boêmio Joe Gould, mencionado na abertura deste artigo, que já havia protagonizado o perfil "Professor Gaivota" [Professor Seagull], publicado na New Yorker em 12 de dezembro de 1942, focado na vida de Gould e no seu empreendimento literário, uma História Oral em que estariam 


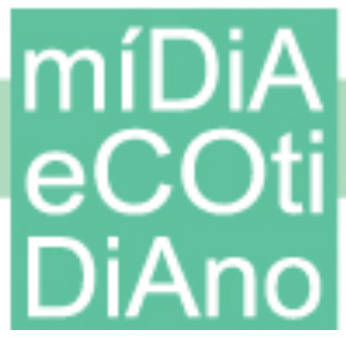

compiladas todas as conversas de bar - a suprema antologia do conhecimento comum, da ideologia do cotidiano. Apesar de a caracterização de Gould em "Professor Gaivota" ser bastante simpática, Mitchell na verdade estava bastante irritado com o entrevistado e fatigado de sua companhia, da qual esperava livrar-se após a publicação do perfil; no entanto, não foi tão simples desvencilhar-se de Gould, que continuou procurando-o por meses e meses, num processo desgastante que acabou desembocando num desmascaramento não-intencional em que Gould revelava que a História Oral, em sua maior parte, não havia sido escrita. Ao contrário da narrativa de "Voodoo in New York, N.Y.”, em que Mitchell procurava em grande parte desmistificar suas fontes e seus saberes, aqui o repórter afirma se sentir bastante mal em expor um outro ser humano como fraude, um indicativo do crescimento de sua empatia ao longo dos anos - a ponto de aguardar quase duas décadas após a descoberta, e sete anos após a morte de Gould, para fazer a revelação pública, indeciso entre respeitar a máscara que seu personagem decidiu vestir (MARTINEZ, 2016) e acertar as contas com um passado em que estava cada vez mais imerso (MITCHELL, 2015).

O ensaio-memorial se constitui num olhar para o abismo em que o foco já não era o projeto de história oral em si, mas o homem por trás dele e suas diversas facetas, iniciando-se por um longo desabafo em que Mitchell apresentava um contraperfil de Gould, caracterizando-o de forma extremamente antipática: um aproveitador, ladrão, ególatra - numa das passagens mais marcantes desse segmento, Gould afirma sofrer de delírios de grandeza por acreditar ser ele próprio. A revelação da inexistência da História Oral - ou pelo menos de $99 \%$ do volume de páginas que Gould afirmava ter escrito - é um ponto de virada na narrativa, que passa a assumir um tom cada vez mais terno conforme Mitchell dialoga as duas facetas de Gould com a sua própria experiência, delineando uma terceira caracterização do boêmio, mais trágica do que farsesca (PASSOS, 2014), na qual sua valorização do conhecimento comum é retomada e reconhecida.

Desta vez, Mitchell não permite que o falecido Gould "fale por si", expressão que uso com reservas, tendo em mente que a representação de uma fonte ou personagem em reportagem sempre se dá a partir de uma construção a partir das lentes ideológicas de um repórter, de suas condições institucionais, e mesmo de um recorte a partir dessas 


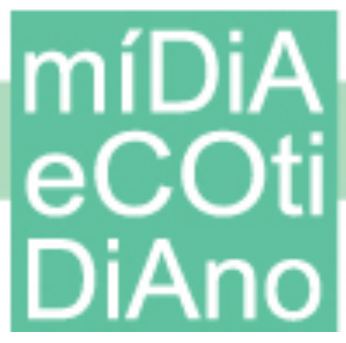

percepções. Desta vez, Mitchell assume uma postura interpretativa, torna-se um narradorcomentador, porém em vez de expor e analisar Gould a partir dos instrumentos da ideologia oficial - e aqui podemos pensar nas diversas disciplinas científicas e acadêmicas publicamente autorizadas a "dissecar" personalidades e comportamentos -, apresenta uma leitura bastante pessoal, e por vezes até passional, na qual prevalecem os diversos e por vezes confusos sentimentos estimulados pela relação repórter-fonte. Mesmo o momento de reconciliação postmortem se dá em termos de identificação com Gould, de compreensão de suas falhas e vícios a partir das próprias falhas e vícios de Mitchell.

\section{O HOMO SAPIENS DEMENS DE MITCHELL}

A comemoração do ser humano e dos saberes comuns está presente ao longo da obra de Mitchell, como pode ser apreendido pelos exemplos apresentados aqui, nos quais o tratamento multifacetado dos personagens se desenvolve de modo a apresentá-los como indivíduos de glórias e derrotas, repletos de luz e sombras, de sabedoria e de estupidez simultaneamente sapiens e demens, nos termos de Maffesoli (1988), ao se referir respectivamente aos elementos de racionalidade e irracionalidade no conhecimento comum, que em condições distintas poderiam ambos levar ao progresso ou ao retrocesso, ao bem e ao mal, à conquista ou à ruína - seja de si, seja de outros. Esse é um dos aspectos em que se concentraria a graça do conhecimento comum, por não ser autoindulgente, nem pretender ocupar um lugar de saber absoluto -, e, o mais importante, progressivamente se despe de posturas interpretativas direcionadas a explicá-los, a conferir-lhes um sentido único, preferindo retratá-los com complexidade - ou compreensividade, no sentido de amplitude de sentidos.

Vimos nos textos de Mitchell discutidos aqui que o saber comum, o conhecimento de praça pública (MAFFESOLI, 1988) - a ideologia do cotidiano (BAKHTIN, 2012) não apenas ocupam um lugar central na narrativa que não é relativizado ou contextualizado a partir de análises de natureza acadêmica - seja psicológica, antropológica, sociológica; mesmo ao se assumir como enunciador em "O Segredo de Joe Gould”, o próprio Mitchell se coloca não como um analista de Gould, mas um dialogante, um interrogante diante do enigma que o protagonista-nêmese representa para si. Não 


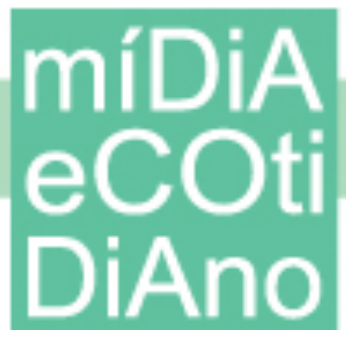

sendo perspectivados por definidores primários, por um tipo de expertise que integra o conjunto da ideologia oficial, os saberes de seus personagens possuem protagonismo discursivo, falam por si próprios e têm respaldo nas histórias de vida relatadas constituindo assim narrativas efetivamente mais compreensivas, ao abraçar o conhecimento comum e tomá-lo como autônomo nessas narrativas.

De modo geral - e sempre com algumas exceções - as narrativas de Mitchell não são em si polifônicas, trazendo em vez disso retratos coesos que, embora por vezes sejam construídos a partir de uma diversidade de fontes, acabam por oferecer apenas uma voz discursiva; o conjunto de sua obra, porém, oferece uma pluralidade de vozes da ideologia do cotidiano. Tendo em mente a proposição de Demétrio de Azeredo Soster (2015) de que o sistema midiático, composto pela complexa rede de dispositivos de mídia, constitui um nível próprio de narração que engloba todo um conjunto de produtos jornalísticos ou mesmo ficcionais em torno de um acontecimento, a circulação de reportagens e perfis que privilegiem o discurso não-oficial - ainda que não polifônicos em si - permite uma oxigenação desse sistema, em geral constituído pela lógica do jornalismo de pirâmide, focada em dar mais autoridade às vozes de definidores primários, da ideologia oficial, institucional; desse modo, pode tornar esse nível de narração mais polifônico ao favorecer a circulação dessas contravozes, girando num fluxo inverso ao da espiral do silêncio.

A perspectiva discursiva do jornalismo literário, num plano mais amplo, pode ter se transformado ao longo do tempo, variando da cobertura de personagens à margem da sociedade nos anos 30 e 40, e de grande temas essencialmente contraculturais durante os anos 60 - os black panthers, protestos contra a Guerra do Vietnã, uso de alucinógenos -, chegando a uma prevalência atual daquilo a que Sims (2007) denomina "Tópico A" - a cobertura de ciência e tecnologia, política, crimes, guerra. Esse é um fenômeno a ser explorado em outros trabalhos: é preciso verificar até que ponto essa tendência de fato suplanta a narrativa do cotidiano, e de que modo as fontes de informação são trabalhadas ali: se há um fortalecimento das instituições constituintes da ideologia oficial ou se há ainda uma valorização do conhecimento comum, da experiência vivida - ou seja, se a orientação ético-discursiva dessas reportagens se constitui a partir dos temas de reportagem ou de uma episteme própria de cada modelo jornalístico. 
O exemplo de Mitchell, em especial do processo de maturação que o transformou de mediador das ideologias oficiais, nas primeiras produções dos anos 1930, a mediador dos saberes comuns nos anos 1940 e 1950, e finalmente um dialogante que confronta e concilia seus próprios saberes com os de seu personagem em 1964. Temos aí uma passagem gradual da agência do pensamento sapiens à celebração do pensamento demens: a uma construção mais complexa da realidade no coletivo de reportagens, perfis e ensaios, cujo motor deixa de ser a reafirmação da ordem sobre um suposto caos cotidiano, em vez disso procurando registrar lampejos fascinantes desse caos que a ordem e a lógica das instituições fazia desaparecer. Uma eventual verificação da valorização da experiência e do saber comum dela decorrente em outros esforços de pesquisa, especialmente em narrativas que privilegiam o "tópico A", permitiria reforçar os pressupostos teóricos deste trabalho, caracterizando o jornalismo literário como um sistema que opera em sentidos paralelos, e por vezes mesmo contrários aos do jornalismo de pirâmide.

\section{Referências}

BAKHTIN, Mikhail. O Freudismo. 2. ed. São Paulo: Perspectiva, 2012.

Problemas da poética de Dostoiévski. Rio de Janeiro: Forense Universitária, 2010. FUNTOWICZ, Silvio O.; RAVETZ, Jerome R. Science for the post-normal age. Futures. v.25, n.7, p.739-755, set. 1993.

HALL, Stuart et al. A produção social das notícias: os mugging nos media. In: TRAQUINA, Nelson (Org.). Jornalismo: Questões, Teorias e "Estórias". Florianópolis: Insular, 2016, p.309341.

KUNKEL, Thomas. Man in profile: Joseph Mitchell of The New Yorker. New York: Random House, 2015.

KÜNSCH, Dimas A.; MENEZES, José Eugenio de O.; PASSOS, Mateus Yuri. Conhecimento, compreensão e cultura: aspectos intersubjetivos e epistemológicos da compreensão como método. ENCONTRO NACIONAL DA COMPÓS, 26. São Paulo: Faculdade Cásper Líbero, 2017. Anais... Brasília: Compós, 2017.

MAFFESOLI, Michel. O Conhecimento Comum. São Paulo: Brasiliense, 1988.

MARTINEZ, Monica. Jornalismo Literário: tradição e inovação. Florianópolis: Insular, 2016. ; CORREIA, Eduardo Luiz; PASSOS, Mateus Yuri. Entre fato e ficção: personagens compostos e fictícios ou fraude em jornalismo?. Estudos em Jornalismo e Mídia, v. 12, n.2, p. 238-250, jul./dez. 2015.

MITCHELL, Joseph. My Ears Are Bent. New York: Pantheon, 2001. A Place of Pasts. The New Yorker, 16 fev. 2015.

Up in the Old Hotel. New York: Pantheon, 2012.

NOELLE-NEUMANN, Elisabeth. The Spiral of Silence. Chicago: Chicago University Press, 1993. 
PASSOS, Mateus Yuri. Jornalismo literário e a pirâmide: implicações discursivas na comunicação pública da ciência. Intercom - Revista Brasileira de Ciências da Comunicação, v.33, n.2, p.199-219, jul./dez. 2010.

. Olhares de relance sobre a Nova York que emerge do silêncio: o jornalismo ensaísticomemorial de Joseph Mitchell. Brazilian Journalism Research. v.13, n.1, p.92-111, jan./abr. 2017.

Perfil e contraperfil: os três Joe Goulds de Joseph Mitchell. In: SOSTER, Demétrio de Azeredo; PICCININ, Fabiana (Orgs.). Narrativas Comunicacionais Complexificadas 2: A forma. Santa Cruz do Sul: EDUNISC, 2014, p.193-213.

PAULY, John. The politics of New Journalism. In: SIMS, Norman (Org.). Literary Journalism in the Twentieth Century. New York: Oxford University Press, 1990, p.120-129.

PERRIN, Noel. Paragon of Reporters: Joseph Mitchell. The Sewanee Review, v.91, n.2, p.167184, 1983.

SCHMITZ, Aldo Antonio. Fontes de Notícias: ações e estratégias das fontes no jornalismo. Florianópolis: Combook, 2011.

SIMS, Norman. Joseph Mitchell and the New Yorker nonfiction writers. In: (Org.). Literary Journalism in the Twentieth Century. Oxford: Oxford University Press, 1990, p.82-109. 2007.

True Stories: a century of literary journalism. Evanston: Northwestern University Press,

SOSTER, Demétrio de Azeredo. A reconfiguração das vozes narrativas no jornalismo midiatizado. Rizoma, v.3, n.1, p.23-35 jul. 2015. 